九州大学学術情報リポジトリ

Kyushu University Institutional Repository

\title{
Fracture Analysis of Resurfaced Femur with Varus Implant Placement
}

Nor Aiman Nor Izmin

Department of Molecular and Material Sciences, Interdisciplinary Graduate School of Engineering Sciences, Kyushu University

Hazwani, Fat in

Department of Molecular and Material Sciences, Interdisciplinary Graduate School of Engineering Sciences, Kyushu University

Todo, Mitsugu

Department of Molecular and Material Sciences, Interdisciplinary Graduate School of Engineering Sciences, Kyushu University

Abdul Halim Abdul lah

School of Mechanical Engineering, College of Engineering, Universiti Teknologi MARA (UiTM)

https://doi.org/10.5109/4738551

出版情報 : Proceedings of International Exchange and Innovation Conference on Engineering \& Sciences (IEICES). 7, pp.7-12, 2021-10-21. 九州大学大学院総合理工学府 バージョン:

権利関係: 


\title{
Fracture Analysis of Resurfaced Femur with Varus Implant Placement
}

\author{
Nor Aiman Nor Izmin ${ }^{1}$, Fatin Hazwani ${ }^{1}$, Mitsugu Todo ${ }^{1,2}$, Abdul Halim Abdullah ${ }^{3}$ \\ ${ }^{1}$ Department of Molecular and Material Sciences, Interdisciplinary Graduate School of Engineering Sciences, Kyushu \\ University, Japan \\ ${ }^{2}$ Research Institute for Applied Mechanics, Kyushu University, Japan \\ ${ }^{3}$ School of Mechanical Engineering, College of Engineering, Universiti Teknologi MARA (UiTM), Malaysia. \\ *Corresponding author email: aimanizmin@gmail.com
}

\begin{abstract}
Clinical reports have mentioned the cases of femoral bone fracture after resurfacing hip arthroplasty which happened to the patients with varus implant placement. This study has conducted fracture analysis by using the finite element method. A 3D inhomogeneous bone model was successfully developed with resurfacing hip implant placed in $6^{\circ}$, $12^{\circ}$, and $18^{\circ}$ varus. The implant model was designed according to the design features of Birmingham Hip Resurfacing. The risk of bone fracture increases as the implant is orientated wider towards the varus placement zone. The initiation of fracture has occurred at the femur that is implanted with varus $18^{\circ}$. Our finding concludes that the distal end of the resurfacing hip implant has a profound effect on the risk of bone fracture.
\end{abstract}

Keywords: Resurfacing hip arthroplasty, Varus implant placement, Femoral bone fracture, Finite element analysis

\section{INTRODUCTION}

Varus implant placement after resurfacing hip arthroplasty (RHA) is often associated as one of the factors that contribute to the fracture of femoral bone [13]. Clinical articles have mentioned the factors that lead to the occurrence of varus implant placement, i.e., surgical, and biomechanical factors [4-7]. The surgical factor can be interpreted based on the surgeons' experience and insertion technique of the implant during hip surgery, while the biomechanical factor is the interaction between the mechanical properties of the bone and the metallic implant. In general, it is noted that experienced surgeons could reduce the possibility of bone fracture after hip arthroplasty, which is proven based on the statistics study conducted by Marker et al. [8]. Thus, the surgical factor is deemed to be less crucial due to the fact that it can be avoided.

In the case of the biomechanical factors, it is known to naturally occur after the insertion of the implant into the femoral bone where the bone failure occurs due to the effect of stress shielding. According to Watanabe et al., [9] the stress shielding phenomenon has greatly affected bone strength due to the stress absorption by the metallic implant. On the other hand, the problem of implant loosening is also possible as a consequence of this phenomenon, resulting in the implant being oriented in varus placement during the loosening process [10]. Since this biomechanical factor could lead to the occurrence of varus implant placement after RHA, it is crucial to understand the bone's condition under this circumstance, considering the case of bone fracture that is related to this type of placement is highly reported among patients, based on the clinical reports.

It is somewhat difficult to collect data through experiments on such cases due to the difficulties in obtaining the cadaver bone, therefore, the simulation work is often adopted. Previous computational studies have discussed the mechanical analysis of the femoral bone which is associated with the implant placement after RHA [11]-[13]. On another note, it is also concluded that different placement of RHA implant has different effects on the bone adaptation [14]. Interestingly, the results from previous computational studies showed that the femur bone with varus implant placement is more vulnerable to the risk of bone fracture.
Therefore, this present study aims to identify the effects of varus implant placement after resurfacing hip arthroplasty and its relation to the bone fracture by using finite element analysis.

\section{MATERIALS \& METHODOLOGY}

Clinical institutions have mentioned that younger patients are more likely to have better outcomes after RHA [15]-[17]. Hence, a computed tomography (CT) image of 47 years old patient has been selected for this study. The patient has been diagnosed with osteoarthritis (OA), which is located on his left femur. The CT image was then imported into a biomechanical software, Mechanical Finder, for the development of a threedimensional (3D) bone model. For the type of mesh, this study has applied the tetrahedral element with a size of $5 \mathrm{~mm}$. All procedures from bone modelling, reconstruction of RHA, and mechanical analysis were done by using this software.

\subsection{Development Method of 3D Bone Model}

The development method of 3D finite element models always becomes a crucial step in a computational study since it will affect the result's reliability. Due to the fact that the bone is anisotropic, non-linear, and nonhomogeneity material, the development of an inhomogeneous bone model should be taken into consideration. The Mechanical Finder software has the ability to develop the inhomogeneous bone model. Based on the linear relationship between CT value (Hounsfield unit) and the apparent density of bone from each CT image, a 3D bone model with the distribution of bone mineral densities (BMD) could be developed [18], [19].

For the generation of the distribution of Young's modulus on the bone model, the evaluation was made according to the average value of BMD [20]-[22]. Table 1 shows the estimation of young's modulus and yield strength, based on the range of BMD. It is worth noting that, an inhomogeneous bone was able to be reproduced in 3D models as shown in Fig. 1. 
Table 1. Estimation of young's modulus and yield strength

\begin{tabular}{ll}
\hline \hline Density range & Young's modulus $(\mathrm{MPa})$ \\
\hline$\rho=0$ & $\mathrm{E}=0.001$ \\
$0<\rho \leq 0.27$ & $\mathrm{E}=33900 \rho^{2.20}$ \\
$0.27<\rho<0.6$ & $\mathrm{E}=5307 \rho^{+469}$ \\
$0.6 \leq \rho$ & $\mathrm{E}=10200 \rho^{2.01}$ \\
$\rho=0$ & $\mathrm{E}=0.001$ \\
\hline Density range & Yield strength $(\mathrm{MPa})$ \\
\hline$\rho \leq 0.2$ & $\sigma \mathrm{r}=1.0 \times 10^{20}$ \\
$0.2<\rho<0.317$ & $\sigma \mathrm{r}=137 \rho^{1.88}$ \\
$0.317 \leq \rho$ & $\sigma \mathrm{r}=114 \rho^{1.72}$ \\
\hline \hline
\end{tabular}

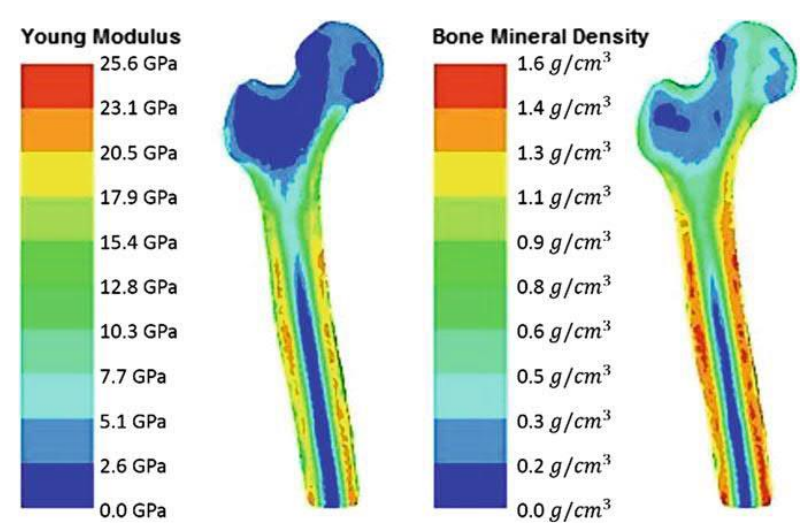

Fig. 1. The distribution of young's modulus and bone mineral density

\subsection{Material Properties of Resurfacing Hip Implant}

The type of implant used in this study is Birmingham Hip Resurfacing (BHR). The femoral head size of the implant is $50 \mathrm{~mm}$. The implant was assigned with the properties of Cobalt-Chromium ( $\mathrm{CoCr}$ ) as shown in Table 2 below.

Table 2. Properties of Cobalt-Chromium (CoCr)

\begin{tabular}{lllll}
\hline \hline $\begin{array}{l}\text { Young } \\
\text { modulus }\end{array}$ & $\begin{array}{l}\text { Poisson } \\
\text { ratio }\end{array}$ & $\begin{array}{l}\text { Critical } \\
\text { stress } \\
(\mathrm{GPa})\end{array}$ & $\begin{array}{l}\text { Yield } \\
\text { stress } \\
(\mathrm{GPa})\end{array}$ & $\begin{array}{l}\text { Density } \\
\left(\mathrm{g} / \mathrm{cm}^{3}\right)\end{array}$ \\
\hline 230 & 0.3 & 0.94 & 2.7 & 8.28 \\
\hline \hline
\end{tabular}

\subsection{Reconstruction of Varus Implant Placement}

As mentioned earlier, this study only focuses on the RHA with varus implant cases. To discuss this matter, it is important to understand the anatomical axis of the femur. According to Amanatullah et al., the placement of the implant could be identified by referring to the orientation angle of its stem. If the stem angle exceeds the anatomical angle of the neck-shaft axis, it will be considered enter the varus zone [23]. The femoral neckshaft axis is important in this reconstruction step which acted as the reference axis (Fig. 2 (a)).

In this study, there are four femoral bone models have been reconstructed with the RHA. One has been implanted with straight implant placement to mimic the clinical procedure, while the other three models were placed in varus zone. The straight implant placement was developed by referring to the anatomical femoral neckshaft axis. After that, for the implanted femur with varus placement, the implant has been oriented in $6^{\circ}, 12^{\circ}$, and $18^{\circ}$ degrees in the varus placement zone. The placements (varus $6^{\circ}, 12^{\circ}$, and $18^{\circ}$ ) were selected to identify the effects of the implant placement on the femoral bone condition as it oriented more towards the varus placement zone, which also possible to happen to the patients who underwent the RHA. Fig. 2 (b) shows the example of the reconstruction of the femur model in $18^{\circ}$ varus placement, where a similar procedure has been used to reconstruct the other implanted femur model.



(a)

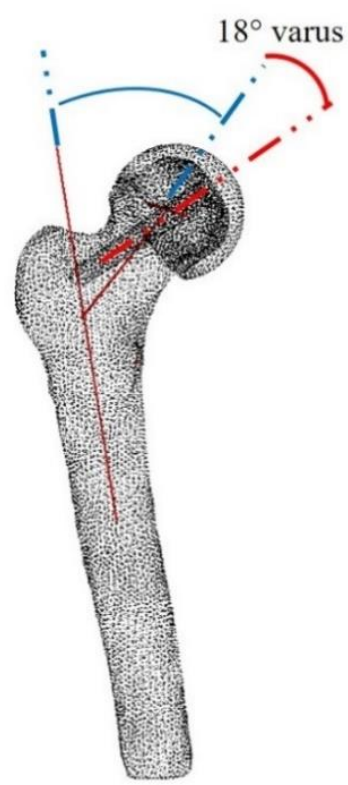

(b)
Fig. 2. The example of (a) femoral neck-shaft axis and (b) the femoral bone model with RHA implant in $18^{\circ}$ varus placement

\subsection{Loading and Boundary Conditions}

The loading values and directions were set according to the condition of normal walking. The condition of walking was selected since it is a common physiological activity for a human. This study simulates the highest load applied to the femur during the one-leg stance phase of walking, based on the calculation made by Bergman et al. [24]. According to the data gained from the experimental study, about $238 \%$ of the load was exerted to the femoral bone head (contact force) during walking activity, which comes from the human body weight (BW). In addition, another loading force that was taken into consideration in this computational study is the abductor muscle force [25]. Heller et al. mentioned that the abductor muscle has produced about $104 \%$ load of BW to the greater trochanter (abductor force) of the femur in this circumstance. Since the patient has a bodyweight of $87.6 \mathrm{~kg}(859.36 \mathrm{~N})$, thus, the applied loads which represent the contact and abductor force are 2045.27 N and 893.73 N, respectively.

The boundary condition was set within the proximal area of the femur, due to the fact that the loads were concentrated within this area during the walking condition. Thus, the shaft and distal area of the femur were eliminated. Fig. 3 shows the example of loading and boundary conditions applied in this study. 


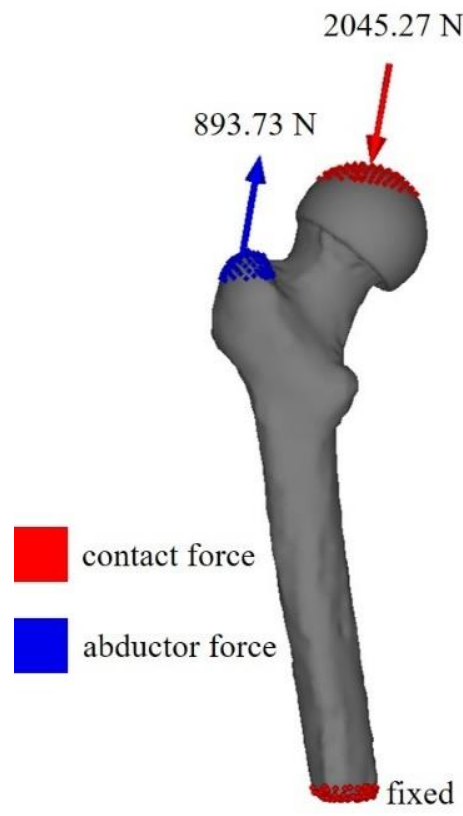

Fig. 3. The loading and boundary condition of walking

\subsection{Criteria of the Failure Elements}

The prediction of fracture formation on the 3D-FEA bone model was based on the failure of the elements after loaded. The element failure can be characterized by two criteria which are the tensile and compressive failure.

According to the data obtained from experimental studies, the ultimate tensile stress for the cortical and cancellous bone are $76 \%$ and $79 \%$ of the compressive yield stress, respectively [26], [27]. Therefore, the failure element in the tensile direction will occur when the maximum principal stress, $\sigma_{\mathrm{p}}$ of the element exceeds 0.8 compressive yield stress, $\sigma_{\mathrm{r}}$.

On another note, the element failure in a compressive direction is based on a two-stage process. The first one is the transition to the yielded state. The element will be in the yield state when the DruckerPrager stress, $\sigma_{D}$ exceeds the yield stress, $\sigma_{\mathrm{r}}$. Next, the element will fail in a compressive direction if the minimum principal strain, $\varepsilon_{\mathrm{p}}$ of the element in the yielded state is lower than -3000 microstrain [27], [28]. Table 3 summarizes the criteria for the element to reach failure.

\section{RESULTS AND DISCUSSION}

The femoral bone model in this study has been validated and described by the current author in the previous study [12].

The prediction of fracture formation in this study was according to the number of failure elements that appeared at the femoral bone model, based on the failure criteria as stated in Table 3. For the mechanical and stress analysis, the results in this study will be based on the DruckerPrager model, which suitable for brittle material such as bones.

\subsection{Number of Failure Elements obtained on the Femoral Bone Models}

Results in Fig. 4 shows the comparison of failure elements between the intact femur, femur with straight implant placement $0^{\circ}$, and femur implanted with varus $6^{\circ}, 12^{\circ}$, and $18^{\circ}$ after loaded. The element failure within the femoral bone has appeared in crushed and cracked solid. Crushed solid is the element that has failed in compressive direction as explained in Table 3, while the cracked solid is the element that failed in the tensile direction.

Based on the results (Fig. 4), there is no failed element occurred at the intact femur as the load applied. For the femur bone implanted in straight placement, one element has failed in the tensile direction (cracked). The number of failed elements is similar for the femur model implanted with $6^{\circ}$ varus; however, it has exponentially increased as the implant oriented towards a wider angle in the varus placement. The number of elements that failed in the tensile direction has increased to 6 and 18 elements for the femur implanted with varus $12^{\circ}$ and $18^{\circ}$, respectively.

On the other hand, the failure element in compressive direction (crushed) has started to appear at the femur model implanted with varus $18^{\circ}$. Based on the result shown in Fig 4, it is understood that the mechanical behaviour of the bone is affected by different implant orientation. Hence, it emphasizes the importance of preventing the incidence of varus placement after the resurfacing hip arthroplasty.

Table 3. Criteria of failure element

\begin{tabular}{|c|c|c|}
\hline Failure category & & Criterion \\
\hline Tensile & $\begin{array}{l}\text { Initiation of } \\
\text { failure } \\
\text { (Cracked) }\end{array}$ & $\sigma_{p}>0.8 \sigma_{r}$ \\
\hline \multirow[t]{2}{*}{ Compressive } & $\begin{array}{l}\text { Transition } \\
\text { to yielded } \\
\text { state } \\
\text { (Plastic) }\end{array}$ & $\sigma_{D}>\sigma_{r}$ \\
\hline & $\begin{array}{l}\text { Initiation of } \\
\text { failure } \\
\text { (Crushed) }\end{array}$ & $\begin{array}{c}\varepsilon_{p}<-3000 \\
\text { (in yielded state) }\end{array}$ \\
\hline \multicolumn{3}{|c|}{$\sigma_{\mathrm{p}}:$ maximum principal stress } \\
\hline \multicolumn{3}{|c|}{$\sigma_{D}:$ Drucker-Prager equivalent stress } \\
\hline \multicolumn{3}{|l|}{$\sigma_{\mathrm{r}}:$ yield stress } \\
\hline$\varepsilon_{\mathrm{p}}:$ minimum pri & cipal strain & \\
\hline
\end{tabular}

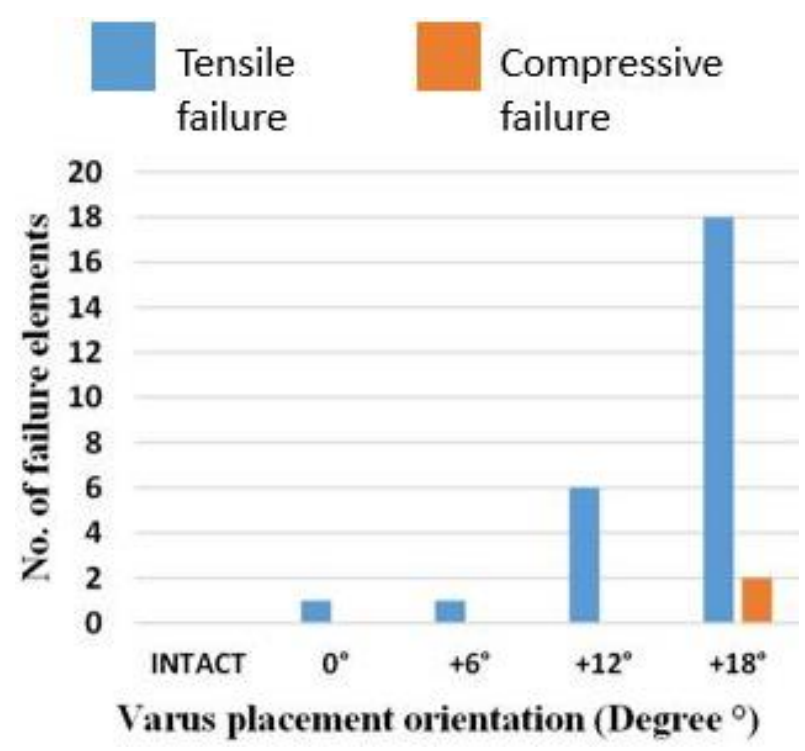

Fig. 4. Number of failure elements of all femur models 


\subsection{Prediction of the Fracture Location within the Femoral Bone}

It is important to identify the location of the failure elements within the femur, to understand the area that is vulnerable to fracture risk due to the effects of implant placement. Fig. 5 shows the fracture formation for all implanted models from the anterior-posterior-superior view. The fracture formation is predicted based on the accumulation of the failure elements within the femur.

Based on the illustration, it can be seen that the location of fracture is almost similar between all models. The failed elements are accumulated within the neck area of the femur, and it is evolving as the implant is oriented wider towards the varus placement zone. This finding suggests that the implant placement has affected the femur area which surrounded by the RHA implant and contributes to the initiation of bone failure within that region. Based on the illustration shown in Fig. 5 (d), the highest accumulation of elements failure was obtained at the femur model implanted with varus $18^{\circ}$ in both tensile and compressive direction. Therefore, to further understand on this situation, the stress analysis was conducted within the neck area of the femur for this model.

(a)

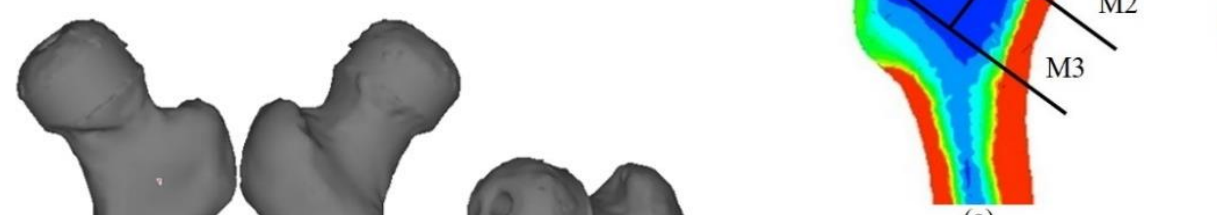

(a) changes between the varus $18^{\circ}$ model and the intact femur. The proximal area of both femur models was divided into six zones, consist of three in the medial (M) and lateral (L) regions, respectively. All six zones were equally divided, which covered the bone area that was surrounded by the presence of the implant. The dividing line between the medial and lateral zone was according to the anatomical neck axis of the femur to ensure the parameter's accuracy for both models, before extracting the stress value for all zones. Fig. 6 shows the example of extraction zones within the proximal area of the femur, and Fig. 7 is the extraction results of stress value for both models.
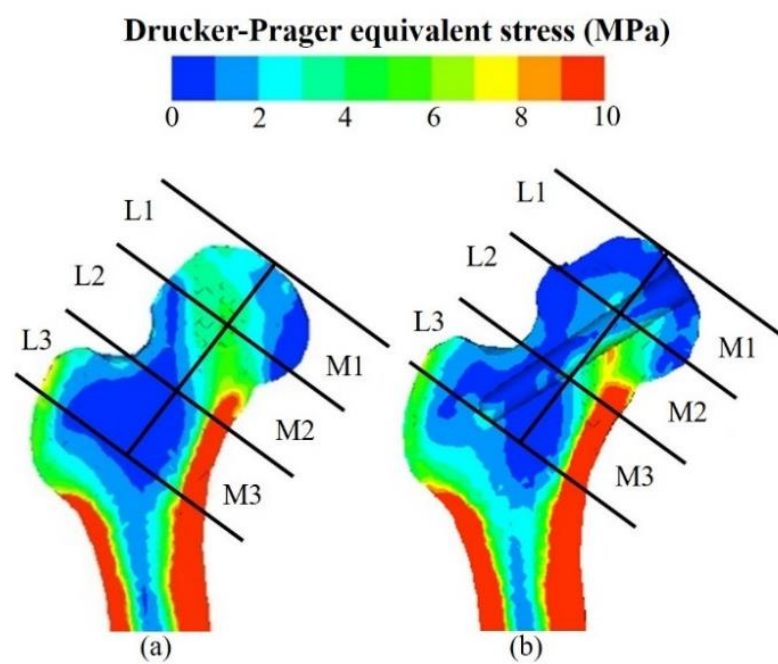

Fig. 6. The extraction zones within the medial and lateral region of the proximal femur of (a) intact (b) varus $18^{\circ}$

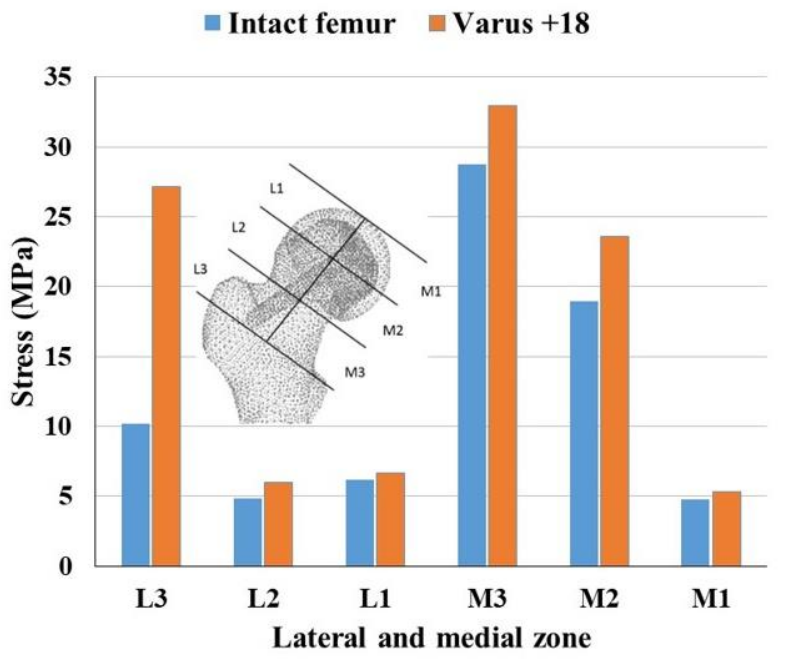

Fig. 7. Maximum stress value of intact and implanted femur (varus $18^{\circ}$ )

Based on the results in Fig. 7, the stress value within the bone for the varus $18^{\circ}$ femur model is higher than the intact femur in every zone. Despite that, the stress increment showed on the M1, M2, M3, L1, and L2 zones are not significant as compared to the intact. For M1 and $\mathrm{L} 1$, the stress has increased by $12 \%$ and $9 \%$ on the implanted femur as compared to the intact. At the M2 and L2 zone, the stress has increased about $24 \%$ and $23 \%$ respectively. For M3, the difference of stress increment also not significant despite it has the highest stress value due to the compressive loading magnitude from the 
contact force. The stress increments between the intact and implanted in this zone are about $14 \%$.

Our focus here is on the L3 zone which has a significant result compared to other zones. A notable difference in stress values can be seen between the intact and implanted femur model. The stress value for the intact femur is $10.15 \mathrm{MPa}$, and it has increased to 27.18 MPa after implanted. About $168 \%$ of stress increment was experienced by the femur bone within this zone. It is assumed that the presence of the distal end of the implant (pin) within the L3 zone is the major factor in this notable increment of stress. The higher stress experience by the femur in this zone might be due to the bending effect produced by the pin after loaded, which is related to the orientation of the RHA implant. In addition, it is proven that most of the elements that failed were accumulated within the L3 region as shown in Fig. 8.

However, according to clinical, the fracture of the femoral bone is considered if the outer surface (shell) of the cortical bone has failed [29]. Since the shell element which represent the outer surface of cortical bone is not assigned in this study, thus, we cannot identify weather the outer cortical bone has experience crack or not under this loading condition. The development of shell elements with inhomogeneous material property of outer cortical bone should be considered in the future studies. Nonetheless, the solid element failures at the femur model were expected to grow and lead to the crack initiation at the outer cortical bone when the femur bone is experiencing the alternating forces from daily activities.

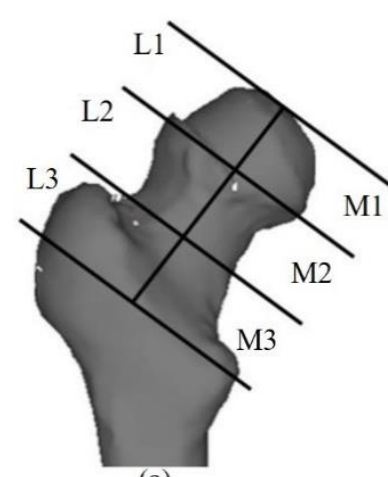

(a)

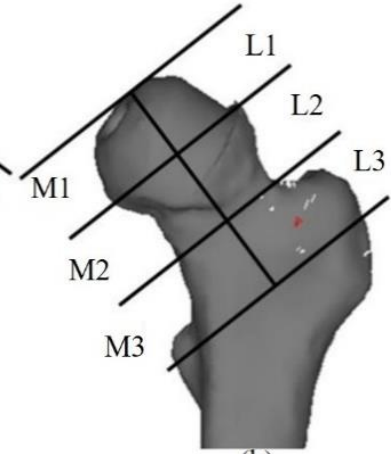

(b)
Fig. 8. Accumulation of failure elements within the L3 zone from (a) posterior and (b) anterior view

\section{CONCLUSION}

The location of the fracture on the femoral bone implanted in varus placement was predicted. It was observed that the fracture occurred at the L3 zone of the neck area of the femur, concluding that this area is the most vulnerable to the risk of fracture. It was confirmed that as the implant oriented wider towards the varus placement zone, the element failed in tensile direction was seen to be accumulated around the neck area, resulting in the initiation of fracture. The mechanical properties such as the maximum stress have been analyzed and discussed. A significant difference in stress increment $(168 \%)$ was seen on the L3 zone after the insertion of the implant due to the bending effect by the implant pin. It thus concluded that this study would be helpful on understanding the importance of implant stability and placement after resurfacing hip arthroplasty.

\section{ACKNOWLEDGEMENTS}

This research was supported by Universiti Teknologi MARA, UiTM under Grant No. 600- IRMI/PERDANA 5/3 BESTARI (103/2018). We thank and acknowledge the Ministry of Education, Malaysia, and our colleagues from the Faculty of Medicine, UiTM, who provided insight and expertise that greatly assisted the research.

\section{REFERENCES}

[1] M.A. Freeman, "Some anatomical and mechanical considerations relevant to the surface replacement of the femoral head.," Clin. Orthop. Relat. Res., vol. 134, pp. 19-24, 1978.

[2] S. B. Bell, R. S, Schatzer, J., Fornaster, V. L., Goodman, "Study of implant failure of the Wagner resurfacing arthroplasty," J. Bone Jt Surg, vol. 67A, pp. 1165-1175, 1987.

[3] B. G. Freeman, M. A. R. Cameron HU, "Cemented Double Cup Arthroplasty of the Hip: A 5 Year Experience with the ICLH Prosthesis," Clin. Orthop., vol. 134, pp. 45-52, 1978.

[4] E. E. Beaule PE, Lee JL, Le Duff MJ, Amstutz $\mathrm{HC}$, "Orientation of the femoral component in surface arthropalsty of the hip: A biomechanical and clinical analysis," J Bone Jt. Surg Am., vol. 86, pp. 2015-2021, 2004.

[5] L. D. M. Amstutz HC, Campbell PA, "Fracture of the neck of the femur after surface arthroplasty of the hip," J Bone Jt. Surg Am., vol. 86, pp. 1874-1877, 2004.

[6] M. C. de Waal Malefijt and R. Huiskes, "A clinical, radiological and biomechanical study of the TARA hip prosthesis," Arch. Orthop. Trauma Surg., vol. 112, no. 5, pp. 220-225, 1993. W. C. Head, "Total articular resurfacing arthroplasty, Analysis of component failure in sixty-seven hips.," J. Bone Jt Surg, vol. 66A, pp. 28-34, 1984.

[8] D. R. Marker, T. M. Seyler, R. H. Jinnah, R. E. Delanois, S. D. Ulrich, and M. A. Mont, "Femoral Neck Fractures After Metal-on-Metal Total Hip Resurfacing. A Prospective Cohort Study," J. Arthroplasty, vol. 22, no. 7 SUPPL., pp. 66-71, 2007.

[9] Y. Watanabe, N. Shiba, S. Matsuo, F. Higuchi, Y. Tagawa, and A. Inoue, "Biomechanical study of the resurfacing hip arthroplasty: Finite element analysis of the femoral component," $J$. Arthroplasty, vol. 15, no. 4, pp. 505-511, 2000.

[10] P. Campbell, K. De Smet, "Case studies of femoral loosening and femoral head collapse in hip resurfacing," The Hip Resurfacing Handbook, pp. 444-453, 2013.

[11] Nor Aiman Nor Izmin, Mitsugu Todo, Abdul Halim Abdullah, "Effects of Varus \& Valgus Implant Malposition in Resurfacing Hip Arthroplasty," in International Exchange and Innovation Conference on Engineering \& Sciences, 2019, pp. 89-92.

[12] Nor Aiman Nor Izmin, Fatin Hazwani, Mitsugu Todo, Abdul Halim Abdullah, "Risk of Bone Fracture in Resurfacing Hip Arthroplasty at Varus and Valgus Implant Placements," Int. J. Technol., vol. 11, no. 5, pp. 1025-1035, 2020.

[13] Nor Aiman Nor Izmin, Mitsugu Todo, Abdul 
Halim Abdullah, "Prediction of bone damage formation in resurfacing hip arthroplasty," Int. J. Eng. Adv. Technol., vol. 9, no. 1, pp. 5879-5885, 2019.

[14] Nor Aiman Nor Izmin, Fatin Hazwani, Mitsugu Todo, Abdul Halim Abdullah, "Computational Analysis on Bone Adaptation in Resurfacing Hip Arthroplasty with Valgus-Varus Placement," in Recent Trends in Manufacturing and Materials Towards Industry 4.0, Springer Singapore, 2021, pp. 179-189.

[15] A. J. Shimmin, J. Bare, and D. L. Back, "Complications associated with hip resurfacing arthroplasty," Orthop. Clin. North Am., vol. 36, no. 2, pp. 187-193, 2005.

[16] D. McMinn and J. Daniel, "History and modern concepts in surface replacement," Proc. Inst. Mech. Eng. Part H J. Eng. Med., vol. 220, no. 2, pp. 239-251, 2006.

[17] J. Daniel, P. B. Pynsent, and D. J. W. McMinn, "Metal-on-metal resurfacing of the hip in patients under the age of 55 years with osteoarthritis," J. Bone Jt. Surg. - Ser. B, vol. 86, no. 2, pp. 177-184, 2004.

[18] M. Todo, "Biomechanical Analysis of Hip Joint Arthroplasties using CT-Image Based Finite Element Method," J. Surg. Res., vol. 01, no. 02, pp. 34-41, 2018.

[19] Nor Aiman Nor Izmin, Fatin Hazwani, Mitsugu Todo, Abdul Halim Abdullah, "Development of Inhomogeneous Femoral Bone Model for CTBased Finite Element Analysis," J. Sci. Eng. Res., vol. 7, no. 6, pp. 98-103, 2020.

[20] J. H. Keyak, S. A. Rossi, K. A. Jones, and H. B. Skinner, "Prediction of femoral fracture load using automated finite element modeling," $J$. Biomech., vol. 31, no. 2, pp. 125-133, 1997.

[21] J. H. Keyak, H. B. Skinner, and J. A. Fleming, "Effect of force direction on femoral fracture load for two types of loading conditions," $J$. Orthop. Res., vol. 19, no. 4, pp. 539-544, 2001.

[22] D. Tawara, J. Sakamoto, H. Murakami, N. Kawahara, J. Oda, and K. Tomita, "Mechanical therapeutic effects in osteoporotic L1-vertebrae evaluated by nonlinear patient-specific finite element analysis," J. Biomech. Sci. Eng., vol. 5, no. 5, pp. 499-514, 2010.

[23] D. F. Amanatullah, Y. Cheung, and P. E. Di Cesare, "Hip Resurfacing Arthroplasty: A Review of the Evidence for Surgical Technique, Outcome, and Complications," Orthop. Clin. North Am., vol. 41, no. 2, pp. 263-272, 2010.

[24] B. G. et al., "Hip contact forces and gait patterns from routine activities," J. Biomech., vol. 34, no. 7, pp. 859-871, 2001.

[25] M. O. Heller, G. Bergmann, J. P. Kassi, L. Claes, N. P. Haas, and G. N. Duda, "Determination of muscle loading at the hip joint for use in preclinical testing," J. Biomech., vol. 38, no. 5, pp. 1155-1163, 2005.

[26] T. M. Keaveny, E. F. Wachtel, C. M. Ford, and W. C. Hayes, "Differences between the tensile and compressive strengths of bovine tibial trabecular bone depend on modulus," $J$. Biomech., vol. 27, no. 9, pp. 1137-1146, 1994.
[27] T. S. Kaneko, M. R. Pejcic, J. Tehranzadeh, and J. H. Keyak, "Relationships between material properties and CT scan data of cortical bone with and without metastatic lesions," Med. Eng. Phys. vol. 25, no. 6, pp. 445-454, 2003.

[28] L. Røhl, E. Larsen, F. Linde, A. Odgaard, and J. Jørgensen, "Tensile and compressive properties of cancellous bone," J. Biomech., vol. 24, no. 12, pp. 1143-1149, 1991.

[29] Dickson KF, Galland MW, Barrack RL, Neitzschman HR, Harris MB, Myers L, "Magnetic resonance imaging of the knee after ipsilateral femur fracture," J. Orthop Trauma, vol. 16, no 8, pp. 567-571, 2002 